\title{
Nitro-polycyclic aromatic hydrocarbons - gas-particle partitioning, mass size distribution, and formation along transport in marine and continental background air
}

\author{
Gerhard Lammel $^{1,2}$, Marie D. Mulder ${ }^{1}$, Pourya Shahpoury ${ }^{2}$, Petr Kukučka ${ }^{1}$, Hana Lišková ${ }^{1}$, Petra Přibylová ${ }^{1}$, \\ Roman Prokeš ${ }^{1}$, and Gerhard Wotawa ${ }^{3}$ \\ ${ }^{1}$ Masaryk University, Research Centre for Toxic Compounds in the Environment, Brno, Czech Republic \\ ${ }^{2}$ Max Planck Institute for Chemistry, Multiphase Chemistry Department, Mainz, Germany \\ ${ }^{3}$ Zentralanstalt für Meteorologie und Geodynamik, Wien, Austria
}

Correspondence to: Gerhard Lammel (lammel@ recetox.muni.cz)

Received: 21 December 2016 - Discussion started: 30 January 2017

Revised: 20 April 2017 - Accepted: 21 April 2017 - Published: 22 May 2017

\begin{abstract}
Nitro-polycyclic aromatic hydrocarbons (NPAH) are ubiquitous in polluted air but little is known about their abundance in background air. NPAHs were studied at one marine and one continental background site, i.e. a coastal site in the southern Aegean Sea (summer 2012) and a site in the central Great Hungarian Plain (summer 2013), together with the parent compounds, PAHs. A Lagrangian particle dispersion model was used to track air mass history. Based on Lagrangian particle statistics, the urban influence on samples was quantified for the first time as a fractional dose to which the collected volume of air had been exposed.
\end{abstract}

At the remote marine site, the 3-4-ring NPAH (sum of 11 targeted species) concentration was $23.7 \mathrm{pg} \mathrm{m}^{-3}$ while the concentration of 4-ring PAHs (6 species) was $426 \mathrm{pg} \mathrm{m}^{-3}$. The most abundant NPAHs were 2nitrofluoranthene (2NFLT) and 3-nitrophenanthrene. Urban fractional doses in the range of $<0.002-5.4 \%$ were calculated. At the continental site, the $\Sigma_{11} 3-4$-ring NPAH and $\Sigma_{6} 4$-ring PAH were 58 and $663 \mathrm{pg} \mathrm{m}^{-3}$, respectively, with 9-nitroanthracene and 2NFLT being the most concentrated amongst the targeted NPAHs. The NPAH levels observed in the marine background air are the lowest ever reported and remarkably lower, by more than 1 order of magnitude, than 1 decade before. Day-night variation of NPAHs at the continental site reflected shorter lifetime during the day, possibly because of photolysis of some NPAHs. The yields of formation of 2NFLT and 2-nitropyrene (2NPYR) in marine air seem to be close to the yields for OH-initiated photochem- istry observed in laboratory experiments under high $\mathrm{NO}_{x}$ conditions. Good agreement is found for the prediction of NPAH gas-particle partitioning using a multi-phase polyparameter linear free-energy relationship. Sorption to soot is found to be less significant for gas-particle partitioning of NPAHs than for PAHs. The NPAH levels determined in the south-eastern outflow of Europe confirm intercontinental transport potential.

\section{Introduction}

Polycyclic aromatic hydrocarbons (PAHs) may undergo chemical transformations in the gaseous and in the particulate phase (Finlayson-Pitts and Pitts, 2000; Keyte et al., 2013). Nitro-PAHs (NPAHs) observed in urban and rural areas (Nielsen et al., 1984; Feilberg et al., 2001; FinlaysonPitts and Pitts, 2000; Keyte et al., 2013) and predicted based on smog-chamber experiments (Atkinson and Arey, 1994) seem to be the most significant derivatives; mutagenicity of atmospheric aerosols in general is mostly related to NPAHs (Grosjean et al., 1983; Garner et al., 1986; Finlayson-Pitts and Pitts, 2000; Claxton et al., 2004; Hayakawa, 2016). A large part, more than one third, of the mutagen potential of ambient aerosols may be attributable to NPAHs (Schuetzle, 1983).

Secondary formation of NPAH from PAHs is thought to occur on short timescales (hours). This has been observed 
for PAHs collected on filters (Ringuet et al., 2012a; Zimmermann et al., 2013; Jariyasopit et al., 2014a, b) as well as in urban plumes (Bamford and Baker, 2003; Arey et al., 1989; Reisen and Arey, 2005). Although many NPAHs are emitted from road traffic, only a few are abundant in this source type (Arey, 1998; Keyte et al., 2013, 2016; Inomata et al., 2015; Alves et al., 2016). The occurrence of various isomers of nitrofluoranthene (NFLT) and nitropyrene (NPYR) can be used to study PAH sources, PAH chemical transformations, and the role of the photo-oxidants hydroxyl radical $(\mathrm{OH})$ and nitrate radical $\left(\mathrm{NO}_{3}\right)$ (Ciccioli et al., 1996; Finlayson-Pitts and Pitts, 2000). For example, 3- and 2-nitrofluoranthene (3-, 2NFLT) is indicative of primary and secondary sources, respectively. These substances have been suggested as tracers for air pollution on the timescales of hours to days (Ciccioli et al., 1996; Finlayson-Pitts and Pitts 2000; Keyte et al., 2013), but their atmospheric lifetimes are still unknown.

Like their precursors, NPAHs are semi-volatile organic compounds (SVOCs), partitioning between the phases of the atmospheric aerosol. Similar to other SVOCs, the NPAHs' phase distribution was found to depend on temperature (summer and winter campaigns in the Alps; Albinet et al., 2008b) and results from both absorptive and adsorptive contributions (Tomaz et al., 2016). NPAHs have primarily been observed in polluted areas (e.g. Pitts et al., 1985; Ramdahl et al., 1986; Garner et al., 1986; Albinet et al., 2007, 2008a; Ringuet et al., 2012a, b; Zimmermann et al., 2012; Barrado et al., 2013; Li et al., 2016), though there are a few studies in rural environments, e.g. in Germany (Ciccioli et al., 1996), in the French Alps (100-1000 $\mathrm{pg} \mathrm{m}^{-3}$ range for the sum of 10 NPAHs; Albinet et al., 2008a), and in northern China (Li et al., 2016). Very few measurements have been performed in a remote atmospheric environment, i.e. in the Mediterranean (Tsapakis and Stephanou, 2007), high-altitude sites in the Himalayas (single data; Ciccioli et al., 1996) and French Alps (Albinet et al., 2008a), and in the Arctic (with so-called Arctic haze; Masclet et al., 1988; Halsall et al., 2001). With regard to the long-range transport potential, the consensus is that at least some NPAHs are expected to go into intercontinental transport (Lafontaine et al., 2015) and might be ubiquitous in the global atmosphere (Ciccioli et al., 1996).

However, there are limited NPAH data from remote atmospheric environments and little is known about their longrange transport potential. The aim of this study was to characterise the long-range transport potential of NPAHs by measurements at remote sites in Europe, addressing the continental background and the outflow of the continent.

\section{Methodology}

\subsection{Sampling}

High-volume air sampling was conducted at a marine background site, Finokalia $\left(35.3^{\circ} \mathrm{N}, 25.7^{\circ} \mathrm{E} ; 250 \mathrm{~m}\right.$ a.s.l.), in the context of a coordinated field experiment from 2 to 13 July 2012 (Lammel et al., 2015) and at a continental background site in central Europe, K-puszta $\left(46^{\circ} 58^{\prime} \mathrm{N}, 19^{\circ} 33^{\prime} \mathrm{E}\right.$; 125 ma.s.l.; Degrendele et al., 2016), from 5 to $16 \mathrm{Au}-$ gust 2013. The Finokalia site is located on a cliff at the northern coast of Crete, some $70 \mathrm{~km}$ east of major significant anthropogenic emissions (Iraklion, a city of 100000 inhabitants with airport and industries; Mihalopoulos et al., 1997; Kouvarakis et al., 2000). The K-puszta site is located in a clearing, characterised by uncultivated grassland, in a mostly coniferous forest in the Hungarian (Pannonian) Great Plain, ca. 70 and $270 \mathrm{~km}$ south-east of Budapest and Vienna, respectively ( $\approx 2 \mathrm{mn}$ inhabitants each). The background site character of both observatories has been previously demonstrated (Borbély-Kiss et al., 1988; Kouvarakis et al., 2000; Vrekoussis et al., 2005). Meteorological parameters and trace gases are measured at both observatories, which are stations of the EMEP network (EMEP, 2015).

High-volume air samples were collected using an HV100P (Baghirra, Prague, Czech Republic), equipped with a multi-stage cascade impactor (Andersen Instruments Inc., Fultonville, New York, USA, series 230, model 235) with five impactor stages, $10-7.2,7.2-3,3-1.5,1.5-0.95$, and $0.95-0.49 \mu \mathrm{m}$, corresponding to aerodynamic particle size, $\mathrm{D}$ (spaced roughly equal $\Delta \log \mathrm{D}$ ), of a backup filter collecting particles $<0.49 \mu \mathrm{m}$ and, downstream, two polyurethane foam plugs (PUFs, Molitan, Břeclav, Czech Republic; density $0.030 \mathrm{~g} \mathrm{~cm}^{-3}$, placed in a glass cartridge), together $10 \mathrm{~cm}$ high. Particles were sampled on slotted QFF substrates (TE-230-QZ, Tisch Environmental Inc., Cleves, USA; $14.3 \times 13.7 \mathrm{~cm}$ ) and glass fibre filters (Whatman, $20.3 \times 25.4 \mathrm{~cm})$. The filters were cleaned prior to use by heating to $108\left(330^{\circ} \mathrm{C}\right)$. PUFs were cleaned $(8 \mathrm{~h}$ extraction in acetone and $8 \mathrm{~h}$ in dichloromethane (DCM)), wrapped in two layers of aluminum foil, placed into zip-lock polyethylene bags, and kept in the freezer prior to deployment. The sampler was operated at a constant flow rate of $68 \mathrm{~m}^{3} \mathrm{~h}^{-1}$. Day-night sampling (changing at sunset and sunrise) of gaseous samples (PUF) was performed at both sites $(12 \mathrm{~h}$, $\left.V \approx 700 \mathrm{~m}^{3}\right)$, while at the marine site the impactor filter (QFF) samples were collected over $24 \mathrm{~h}(n=5)$ or $48 \mathrm{~h}(3)$.

Particle number concentration, $N$, was determined by an optical particle counter (Grimm model 107, Ainring, 31 channels between 0.25 and $32 \mathrm{~mm}$ of aerodynamic particle diameter). Aerosol surface concentration, $\mathrm{S}\left(\mathrm{cm}^{-1}\right)$, was derived as $S=\pi \Sigma_{i} N_{i} D_{i}^{2}$ assuming sphericity. Hereby, true $S$ will be underestimated, in particular if particles of irregular form were abundant (e.g. Jaenicke, 1988). Comparisons with absolute methods (e.g. Pandis, et al., 1991) suggest that the discrepancy may reach up to a factor of 2-3. The mass median diameter $\left(D_{\mathrm{m}}, \mu \mathrm{m}\right)$ was derived as $\log D_{\mathrm{m}}=\Sigma_{i}$ $m_{i} \log D_{i} / \Sigma_{i} m_{i}$, with $m_{i}$ denoting the mass in size class $i$ and $D_{i}$ being the geometric mean diameter collected on stage $i$ of the cascade impactor. 


\subsection{Chemical analysis}

All air samples were extracted with DCM using an automatic warm Soxhlet extractor (Büchi B-811, Switzerland). Deuterated PAHs (D8-naphthalene, D10-phenanthrene, D12perylene; Wellington Laboratories, Canada) were used as surrogate standards for both PAHs and NPAHs. Deuterated PAHs proved to be suitable surrogate standards for NPAHs. These were spiked on each PUF prior to extraction. The extract was split in two parts: $1 / 10$ for PAHs and nitro-PAHs analysis and 9/10 for PBDEs, PCBs, and OCPs. The PAHs and nitro-PAHs aliquot were subject to open column chromatography clean-up. A glass column $(1 \mathrm{~cm}$ i.d.) was filled with $5 \mathrm{~g}$ activated silica $\left(150^{\circ} \mathrm{C}\right.$ for $\left.12 \mathrm{~h}\right)$ and the sample was loaded and eluted with $10 \mathrm{~mL} n$-hexane, followed by $40 \mathrm{~mL}$ DCM. The cleaned sample was evaporated under a stream of nitrogen in a TurboVap II apparatus (Biotage, Sweden), transferred into a conical GC vial, and spiked with recovery standard, terphenyl; the volume was reduced to $100 \mu \mathrm{L}$.

GC-MS analysis of 4-ring PAHs (fluoranthene (FLT), pyrene (PYR), benzo(b)fluorene (BBN), benzo(a)anthracene (BAA), triphenylene (TPH), and chrysene (CHR)) and 2-4ring NPAHs (1- and 2-nitronaphthalene (1-, 2NNAP), 3- and 5-nitroacenaphthene (3-, 5NACE), 2-nitrofluorene (2NFLN), 9-nitroanthracene (9NANT), 3- and 9-nitrophenanthrene (3-, 9NPHE), 2- and 3NFLT, 1- and 2-nitropyrene (1-, 2NPYR), 7-nitrobenz(a)anthracene (7NBAA), 6-nitrochrysene (6NCHR)) was performed using a gas chromatograph atmospheric pressure chemical ionization tandem mass spectrometer (GC-APCI-MS/MS) instrument, Agilent 7890A GC (Agilent, USA), equipped with a $60 \mathrm{~m} \times 0.25 \mathrm{~mm} \times 0.25 \mu \mathrm{m}$ DB-5MSUI column (Agilent, J\&W, USA), coupled to Waters Xevo TQ-S (Waters, UK). Injection was $1 \mu \mathrm{L}$ splitless at $280^{\circ} \mathrm{C}$, with $\mathrm{He}$ as carrier gas at constant flow $1.5 \mathrm{~mL} \mathrm{~min}^{-1}$. The $\mathrm{GC}$ oven temperature program was as follows: $90^{\circ} \mathrm{C}(1 \mathrm{~min}), 40^{\circ} \mathrm{C} \mathrm{m^{-1 }}$ to $150^{\circ} \mathrm{C}, 5^{\circ} \mathrm{C} \mathrm{min}-1$ to $250^{\circ} \mathrm{C}$ (5 min), and $10^{\circ} \mathrm{C} \mathrm{min}^{-1}$ to $320^{\circ} \mathrm{C}(5 \mathrm{~min})$. APCI was used in charge transfer conditions. The isomers 2- and 3NFLT were not separated by the GC method but were co-eluted and are reported as sum.

Recovery of native analytes varied $72-102 \%$ for PAHs and deuterated PAHs and $70-110 \%$ for NPAHs (for details see Supplement, Table S1a). The results were not recovery corrected. The mean of field blank values was subtracted from the sample values. Values below the mean +3 standard deviations of the field blank values were considered to be $<$ LOQ (limit of quantification). Field blank values of some analytes in air samples were below the instrument limit of quantification (ILOQ), which corresponded to 0.004$0.069 \mathrm{pg} \mathrm{m}^{-3}$ for NPAHs (except for 1NNAP, for which it ranged from 0.60 to $0.87 \mathrm{pg} \mathrm{m}^{-3}$ ) and $0.010-0.126 \mathrm{pg} \mathrm{m}^{-3}$ for 4-ring PAHs (except for FLT and PYR, for which it ranged from 0.17 to $0.59 \mathrm{pg} \mathrm{m}^{-3}$ ) (Supplement Table S1).

Higher LOQs were determined for some of the NPAHs and for all 4-ring PAHs in gaseous air samples (PUFs), namely $0.006-0.009 \mathrm{ng}$ (corresponding to $3.5-8.0 \mathrm{pg} \mathrm{m}^{-3}$ ) for 3NACE and 2NPYR; 0.028-0.097 (corresponding to 16$86 \mathrm{pg} \mathrm{m}^{-3}$ ) for 2NNAP, 2NFLT, and 1NPYR; and 0.10 $0.27 \mathrm{ng}$ (corresponding to $\approx 60-240 \mathrm{pg} \mathrm{m}^{-3}$ ) for 4-ring PAHs (except for FLT and PYR, for which it was 1.71 and $1.05 \mathrm{ng}$, respectively, corresponding to $\approx 600-1500 \mathrm{pg} \mathrm{m}^{-3}$ ). In particulate-phase samples, where separate field blanks for the two different QFFs were determined (on the impactor stages on one hand and the backup filter on the other hand), higher LOQs were determined for some of the NPAHs and for all 4-ring PAHs, namely $0.008-0.089 \mathrm{ng}$ (corresponding to $4.6-79 \mathrm{pg} \mathrm{m}^{-3}$ ) for 2NNAP, 2NFLT, 1NPYR, and 2NPYR; $0.26-0.31 \mathrm{ng}$ (corresponding to $150-274 \mathrm{pg} \mathrm{m}^{-3}$ ) for 9NANT; and $0.05-0.22 \mathrm{ng}$ (corresponding to $\approx 30$ $200 \mathrm{pg} \mathrm{m}^{-3}$ ) for 4-ring PAHs (except for FLT and PYR, for which it was 0.79 and $0.36 \mathrm{ng}$, respectively, corresponding to $\approx 200-700 \mathrm{pg} \mathrm{m}^{-3}$ ).

The breakthrough in PUF samples was estimated (Pankow, 1989; ACD, 2015; Melymuk et al., 2016) and, as a consequence, 2-3-ring PAHs and 2-ring NPAHs results were excluded from this study as their sampling may have been incomplete. We therefore report $\Sigma_{6} 4$-ring PAH and $\Sigma_{11} 3-4$ ring NPAH.

Particulate matter mass $\left(\mathrm{PM}_{10}\right)$ was determined by gravimetry (microbalance, filters accommodated to stable temperature and humidity, three replicate weighings) and organic matter (OM) and elemental carbon (EC) contents of PM by a thermal-optical method (Sunset Laboratory, USA; EUSAAR protocol).

\subsection{Gas-particle partitioning}

Gas-particle partitioning was studied by applying a multiphase ppLFER model, which was recently introduced (Shahpoury et al., 2016). In brief, partitioning of semi-volatile compounds in air can be described (Yamasaki et al., 1982) by

$K_{\mathrm{p}}=c_{i \mathrm{p}} /\left(c_{i \mathrm{~g}} \times c_{\mathrm{PM}}\right)$,

where $K_{\mathrm{p}}\left(\mathrm{m}^{3}\right.$ air $\left.(\mathrm{g} \mathrm{PM})^{-1}\right)$ is the temperature-dependent partitioning coefficient, $c_{\mathrm{PM}}\left(\mathrm{g} \mathrm{m}^{-3}\right)$ is the concentration of particulate matter in air, and $c_{i \mathrm{p}}$ and $c_{i \mathrm{~g}}$ are the analyte $(i)$ concentrations $\left(\mathrm{ng} \mathrm{m}^{-3}\right)$ in the particulate and gas phase, respectively. $K_{\mathrm{p}}$ can be predicted using models based on single-parameter and poly-parameter linear free-energy relationships (spLFER, ppLFER). spLFERs relate the partitioning coefficient to one physicochemical property, i.e. assume one process to determine the sorption process, while ppLFERs in principle account for all types of molecular interactions between solute and matrix (Goss and Schwarzenbach, 2001). The observed particulate mass fraction data, $\theta=c_{\mathrm{p}} /\left(c_{\mathrm{g}}+c_{\mathrm{p}}\right)$ (Table 2$)$, were tested with both a spLFER and a ppLFER model. The spLFER chosen is the widely used $K_{\text {oa }}$ model of Finizio et al. (1997) (results presented in the Supplement, Sect. S2.3). The ppLFER is a multi-phase 
model recently presented (Shahpoury et al., 2016) and applied for NPAHs (Tomaz et al., 2016). It is based on linear solvation energy relationships (Abraham, 1993; Goss, 2005):

$\log K_{\mathrm{p}}=e E+s S+a A+b B+l L+c$,

$\log K_{\mathrm{p}}=s S+a A+b B+v V+l L+c$,

where $E, S, A, B, L$, and $V$ are solute-specific Abraham solvation parameters for excess molar refraction (describes interactions between $\pi$ and lone ( $n$ ) electron pairs), polarizability/dipolarity, solute H-bond acidity, solute H-bond basicity, logarithm of solute hexadecane-air partitioning coefficient (unitless), and McGowan molar volume $\left(\mathrm{cm}^{3} \mathrm{~mol}^{-1}\right) / 100$, respectively (Endo and Goss, 2014). The corresponding parameters $e, s, a, b, l$, and $v$ reflect matrix-specific soluteindependent contribution to $K_{\mathrm{p}}$. Due to the lack of experimental data, the solute descriptors for NPAHs were taken from M. H. Abraham (personal communication, 2015). The multi-phase ppLFER considers adsorption onto soot, $\left(\mathrm{NH}_{4}\right)_{2} \mathrm{SO}_{4}$, and $\mathrm{NH}_{4} \mathrm{Cl}$ and absorption into particulate $\mathrm{OM}$. $\mathrm{OM}$ is assumed to be constituted of two separate phases. For these, ppLFER equations for dimethyl sulfoxide-air (representing the low molecular mass range of both organicsoluble and water-soluble $\mathrm{OM}$ ) and for polyurethane etherair (representing the high-molecular-mass organic-soluble OM) are used (Shahpoury et al., 2016). A conventional single-parameter LFER $\left(K_{\mathrm{oa}}\right)$ model is applied, too.

\subsection{Air mass history analysis}

The HYSPLIT (Draxler and Rolph, 2003) and FLEXPART (Stohl et al., 1998, 2005) models were used to identify air mass histories over 10 and 2 days, respectively. The possible influence of polluted air on samples was quantified using a novel method of applying Lagrangian particle statistics (FLEXPART, see Sects. 2.5 and S2.1.2). To this end, for the entire sampling period, one particle per second was released. The model output is generated at $0.062^{\circ}(\approx 7 \mathrm{~km})$, every $30 \mathrm{~min}$, and expressed as "residence time", i.e. a measure of the time particles resided in grid cells. ECMWF meteorological data $\left(0.125^{\circ} \times 0.125^{\circ}\right.$ resolution, hourly) were used as input.

\subsection{Quantification of urban influence on samples}

The potential urban influence for individual samples collected at the marine site was based on the fraction of released Lagrangian particles that travelled through an urban boundary layer. A backward run from the sampling site was performed with Lagrangian particles (i.e. air parcels) being released during the entire sampling period. Three urban areas were considered: Izmir $(\approx 300 \mathrm{~km}$ direct distance; 38.2 $\left.38.8^{\circ} \mathrm{N}, 26.2-27.3^{\circ} \mathrm{E}\right)$, Athens $\left(\approx 300 \mathrm{~km} ; 37.8-38.1^{\circ} \mathrm{N}\right.$, $\left.23.5-23.8^{\circ} \mathrm{E}\right)$, and Istanbul ( $\approx 500 \mathrm{~km}$ away; $40.8-41.1^{\circ} \mathrm{N}$, $\left.28.6-29.5^{\circ} \mathrm{E}\right)$.
The urban fractional dose, $D_{\mathrm{u} i}$, which an air mass collected in sample $i$ had received during a given simulation period $\Delta t$, can be derived as

$D_{u i}=\Sigma_{t} N_{\text {blua }}(t) \times \Delta t_{\text {Rblua }} /\left(N_{\text {tot }}(t) \times \Delta t_{i}\right)$,

where $N_{\text {blua }}(t)$ is the number of virtual particles within the urban boundary layer during the specific time step, model output time resolution $\Delta t_{\text {Rblua }}$ is $0.5 \mathrm{~h}$, and $N_{\text {tot }}(t)$ is the number of virtual particles present during the specific time step. Under the given flow conditions in the region, a 2-day time horizon is considered here. Hence, the simulation period is given as

$\Delta t_{i}=\Delta t_{\text {sample }}+48 \mathrm{~h}$,

with $\Delta t_{\text {sample }}$ being the sampling time. $D_{\mathrm{u} i}$ takes values between 0 and 1 , corresponding to none or all, respectively, of the entire sample of air that crossed the urban boundary layer. The $D_{\mathrm{u}}$ time series with allocation to three urban areas is shown in Fig. S3.

The comparison of urban influence in samples of various sample volume, $V$, requires normalisation to $V$, a relative dose $D_{r \mathrm{u} i}$ (Eq. 6, with $n$ being total number of samples collected). Values of $D_{r \mathrm{u} i}$ may exceed 1.

$D_{r u i}=\left[\Sigma_{n} V_{n} /\left(n V_{i}\right)\right] \times D_{u i}$

The accuracy of the urban fractional dose, $D_{u i}$, is limited by the meteorological input data (here $0.125^{\circ} \times 0.125^{\circ}$ resolution, hourly) and boundary layer depth calculation. In the FLEXPART model, the latter is done according to Vogelezang and Holtslag (1996).

\section{Results and discussion}

The NPAH levels are distinctly lower at the marine than at the continental site, $\Sigma_{11} 3-4$-ring $\mathrm{NPAH}=22.5$ and $58.5 \mathrm{pg} \mathrm{m}^{-3}$, respectively (Table 1). The NPAHs showing the highest concentrations were 2NFLT and 3NPHE at the marine site (Fig. 1b) and 9NANT and 2NFLT at the continental site (Fig. 1d, Table 2). The substance patterns (composition of NPAH mixture) at both sites are similar, however $\left(R^{2}=0.76, P>0.99, t\right.$ test $)$. At the marine site, advection was northerly, with air masses originating (time horizon of 10 days) in eastern and central Europe and, towards the end of the campaign, in the western Mediterranean. The site was placed into the south-eastern outflow of Europe. $\mathrm{NO}_{x}(0.2-0.6 \mathrm{ppbv})$, EC $\left(0.2-0.8 \mu \mathrm{g} \mathrm{m}^{-3}\right)$, and $\mathrm{PM}_{10}(18.3-$ $39.3 \mathrm{\mu g} \mathrm{m}^{-3}$ ) reflect background conditions. Air mass history analysis suggests that the somewhat elevated concentration in the first sample collected at the marine site (Fig. 1a) is related to long-range transport influenced by passage over the urban areas of Izmir and Istanbul (urban fractional dose $D_{\mathrm{u}}=5.0 \%$, in contrast to the mean of $1.6 \%$; Fig. S3). Overall, urban fractional dose in the range $<0.002-5.4 \%$ was received at the marine site. Across all samples at the marine 
(a)

(b)
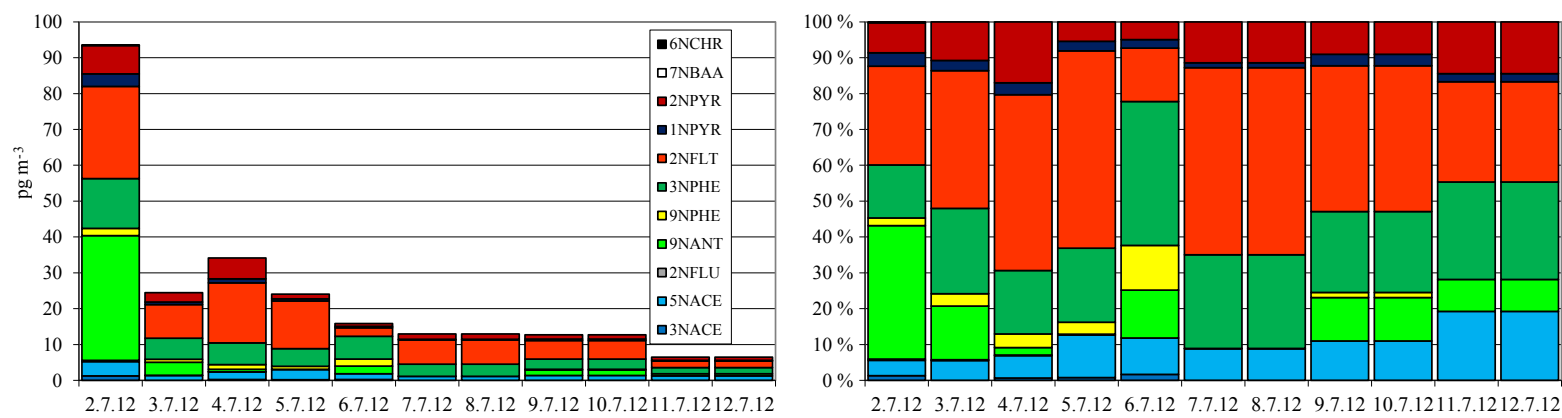

(c)

(d)
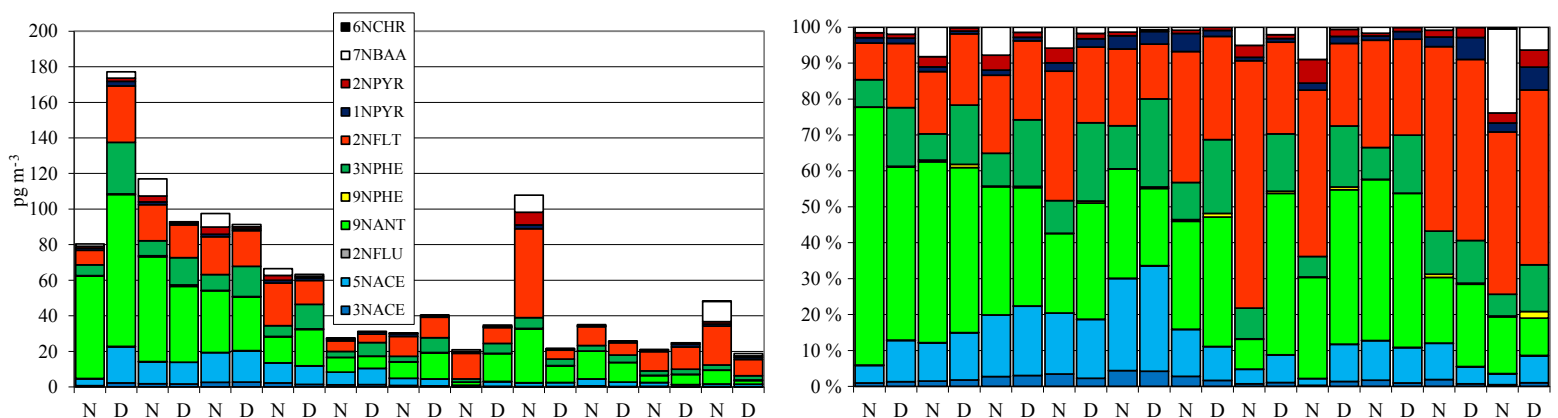

Figure 1. Time series of absolute $\left(\mathbf{a}, \mathbf{c} ; \mathrm{pg} \mathrm{m}^{-3}\right)$ and relative $(\mathbf{b}, \mathbf{d})$ total (gas + particulate) NPAH concentrations at the $(\mathbf{a}, \mathbf{b})$ marine $(24 \mathrm{~h}$ means shown) and (c, d) continental site (day-night means). At the marine site, the gas phase (PUF) was sampled for individual daytimes and nighttimes while the particulate phase (filter) was sampled over 24 or $48 \mathrm{~h}$ ( $48 \mathrm{~h}$ during the period of 7-12 July 2012).

Table 1. Overview of time-weighted mean concentrations in the particulate and gas phases and ambient temperature. Data subsets (B is background, $\mathrm{P}$ is polluted, $\mathrm{D}$ is day mean, $\mathrm{N}$ is night mean) and mass size distribution $(<0.45 / 0.45-0.95 / 0.95-1.5 / 1.5-3.0 / 3.0-7.2 / 7.2-$ $10 \mu \mathrm{m}$ aerodynamic equivalent diameter) in parentheses.

\begin{tabular}{|c|c|c|c|}
\hline Site & Phase & $\Sigma_{11} 3$-4-ring NPAH $\left(\mathrm{pg} \mathrm{m}^{-3}\right)$ & $\Sigma_{6} 4$-ring PAH $\left(\mathrm{pg} \mathrm{m}^{-3}\right)$ \\
\hline \multirow[t]{3}{*}{ Marine } & particulate $(n=8)$ & $\begin{array}{l}4.1(3.5 / 0.6 / 0.2 / 0.03 / 0.03 / 0.00) \\
(\mathrm{B}: 0.2 / \mathrm{P}: 8.7)\end{array}$ & $\begin{array}{l}43 \text { (28/8.1/1.2/6.2/4.3/1.7) } \\
\text { (B: 7.9/P: 42.4) }\end{array}$ \\
\hline & $\operatorname{gas}(n=21)$ & 18.4 (B: 13.2/P:31.1) & 403 (B:321/P:580) \\
\hline & $T\left({ }^{\circ} \mathrm{C}\right)$ & \multicolumn{2}{|c|}{25.6 (B: 27.1/P: 22.0) } \\
\hline \multirow[t]{3}{*}{ Continental } & particulate $(n=22)$ & $\begin{array}{l}24.3(20.5 / 2.9 / 0.7 / 0.04 / 0.06 / 0.15) \\
(\mathrm{D}: 13.9 / \mathrm{N}: 34.6)\end{array}$ & $\begin{array}{l}129(87 / 28 / 12 / 0.6 / 0.0 / 0.0) \\
(\mathrm{D}: 146 / \mathrm{N}: 116)\end{array}$ \\
\hline & gas $(n=22)$ & $34.2(\mathrm{D}: 42.9 / \mathrm{N}: 25.5)$ & 517 (D:649/N:384) \\
\hline & $\mathrm{T}\left({ }^{\circ} \mathrm{C}\right)$ & \multicolumn{2}{|c|}{$23.1(\mathrm{D}: 28.8 / \mathrm{N}: 17.5)$} \\
\hline
\end{tabular}

site, $D_{\mathrm{u}}$ is found to be significantly correlated with the pollutant sum concentrations $\Sigma_{6} 4$-ring PAH and $\Sigma_{11} 3$-4-ring NPAH $\left(R^{2}=0.61\right.$ and 0.69 , respectively; both $\left.P>0.99\right)$.

From the marine site data set, subsets of each two samples are formed, representing the minimum, i.e. almost no influence from industrialised area $48 \mathrm{~h}$ prior to arrival (henceforth called "marine background", urban fractional dose $D_{\mathrm{u}}=0.4 \%$ ), and maximum observed influence (henceforth called "background with urban influence", $D_{\mathrm{u}}=3.1 \%$; Table S2, Fig. S3). The results for these subsets are listed in Tables 1-3. Such classification was not deemed meaningful for the samples collected at the continental site, as the relevant source distribution in central Europe was too homogeneous during this episode. Advection was mostly from the northwest and partly from easterly directions, with air mass origin (time horizon of 10 days) mostly in central Europe and, to a 
Table 2. Total $(\mathrm{g}+\mathrm{p})$ time-weighted concentrations, $\mathrm{c}_{\text {tot }}\left(\mathrm{pg} \mathrm{m}^{-3}\right)$, particulate mass fraction, $\theta=c_{\mathrm{p}} / c_{\text {tot }}$, and mass median diameter $(\mathrm{MMD}$, $\mu \mathrm{m})$ of 2-4-ring NPAHs and 4-ring PAHs at the marine (as "mean (background mean/urban influence mean)", $n=8\left(2^{\mathrm{a}} / 2^{\mathrm{b}}\right)$ ), and continental (as "mean (day mean/night mean)", $n=22(11 / 11)$ ) sites, together with temperature and supporting aerosol parameters (PM 10 and carbonaceous mass fractions). LOQ is the limit of quantification and nd indicates no data.

\begin{tabular}{|c|c|c|c|c|c|c|}
\hline & \multicolumn{3}{|c|}{ Marine } & \multicolumn{3}{|c|}{ Continental } \\
\hline & $c_{\text {tot }}\left(\mathrm{pg} \mathrm{m}^{-3}\right)$ & $\Theta$ & MMD $(\mu \mathrm{m})$ & $c_{\mathrm{tot}}\left(\mathrm{pg} \mathrm{m}^{-3}\right)$ & $\Theta$ & $\operatorname{MMD}(\mu \mathrm{m})$ \\
\hline FLT & $226(161 / 259)$ & $0.07(0.03 / 0.07)$ & $0.58(0.43 / 0.52)$ & $342(432 / 251)$ & $0.11(0.11 / 0.12)$ & $0.062(0.101 / 0.034)$ \\
\hline PYR & $158(103 / 188)$ & $0.04(0.01 / 0.05)$ & $0.21(0.022 / 0.22)$ & $226(276 / 176)$ & $0.18(0.18 / 0.19)$ & $0.075(0.105 / 0.055)$ \\
\hline BBN & $4.1(2.0 / 5.5)$ & 0.01 (nd/0.05) & 0.022 (nd/0.022) & $15(16 / 13)$ & $0.61(0.58 / 0.65)$ & $0.079(0.127 / 0.053)$ \\
\hline BAA & $2.8(<\mathrm{LOQ} / 3.4)$ & 0.28 (nd/0.29) & $0.022(\mathrm{nd} / 0.022)$ & $16(14 / 18)$ & $0.91(0.90 / 0.92)$ & $0.070(0.090 / 0.060)$ \\
\hline TPH & $12(8.5 / 14)$ & $0.02(\mathrm{nd} / 0.05)$ & $0.022(\mathrm{nd} / 0.022)$ & $23(26 / 21)$ & $0.51(0.41 / 0.63)$ & $0.070(0.090 / 0.057)$ \\
\hline CHR & $23(10 / 29)$ & $0.22(0.09 / 0.20)$ & $0.15(0.022 / 0.15)$ & $41(44 / 38)$ & $0.75(0.71 / 0.80)$ & $0.074(0.105 / 0.055)$ \\
\hline$\Sigma_{6} 4$-ring PAH & $426(284 / 499)$ & $0.07(0.02 / 0.07)$ & $0.31(0.19 / 0.28)$ & $663(808 / 517)$ & $0.21(0.19 / 0.25)$ & $0.071(0.10 / 0.051)$ \\
\hline 3NACE & $0.21(0.17 / 0.39)$ & $0.05(0.00 / 0.14)$ & $0.022(\mathrm{nd} / 0.022)$ & $1.0(1.0 / 1.0)$ & $0.05(0.01 / 0.11)$ & $0.022(\mathrm{nd} / 0.022)$ \\
\hline 5NACE & $1.8(1.5 / 2.0)$ & $0.07(0.00 / 0.00)$ & $0.022(\mathrm{nd} / \mathrm{nd})$ & $6.8(7.6 / 6.0)$ & $0.03(0.01 / 0.05)$ & $0.022(0.022 / 0.022)$ \\
\hline $2 \mathrm{NFLN}$ & $0.01(<\mathrm{LOQ} / 0.15)$ & $0.02(\mathrm{nd} / 0.00)$ & 1.19 (nd/nd) & $0.035(0.035 / 0.034)$ & $0.00(0.00 / 0.00)$ & nd \\
\hline 9NPHE & $0.73(0.84 / 0.55)$ & $0.00(0.00 / 0.00)$ & nd & $0.21(0.28 / 0.13)$ & $0.36(0.43 / 0.20)$ & $0.022(0.022 / \mathrm{nd})$ \\
\hline $3 \mathrm{NPHE}$ & $4.8(3.4 / 5.0)$ & $0.00(\mathrm{nd} / \mathrm{nd})$ & nd & $7.4(10.0 / 4.8)$ & $0.24(0.15 / 0.44)$ & $0.109(0.067 / 0.116)$ \\
\hline 9NANT & $4.2(1.1 / 8.2)$ & $0.00(0.00 / 0.00)$ & nd & $22(22 / 22)$ & $0.23(0.14 / 0.33)$ & $0.022(0.022 / 0.022)$ \\
\hline $2 \mathrm{NFLT}^{\mathrm{c}}$ & $8.6(3.8 / 11)$ & $0.32(\mathrm{nd} / 0.45)$ & $0.040(\mathrm{nd} / 0.080)$ & $15(13 / 18)$ & $0.78(0.54 / 0.95)$ & $0.054(0.035 / 0.050)$ \\
\hline 1NPYR & $0.75(0.21 / 1.4)$ & $0.33(0.00 / 0.58)$ & $0.061(\mathrm{nd} / 0.14)$ & $1.1(1.1 / 1.2)$ & $0.82(0.76 / 0.88)$ & $0.030(0.031 / 0.029)$ \\
\hline 2NPYR & $2.5(0.92 / 3.3)$ & $0.53(0.19 / 0.69)$ & $0.058(0.060 / 0.055)$ & $1.3(0.73 / 2.0)$ & $0.93(0.83 / 0.97)$ & $0.070(0.040 / 0.061)$ \\
\hline 7NBAA & $<$ LOQ & nd & nd & $2.5(0.77 / 4.2)$ & $0.91(0.56 / 0.97)$ & $0.074(0.038 / 0.057)$ \\
\hline 6NCHR & $0.02(<\mathrm{LOQ} / 0.07)$ & $1.00(\mathrm{nd} / 1.00)$ & $2.12(\mathrm{nd} / 2.12)$ & $0.01(<\mathrm{LOQ} / 0.02)$ & $1.00(\mathrm{nd} / 1.00)$ & $0.022(\mathrm{nd} / 0.022)$ \\
\hline$\Sigma_{11} 3$-4-ring NPAH & $23.7(11.8 / 32.0)$ & $0.22(0.01 / 0.22)$ & $0.34(0.33 / 0.34)$ & $58(56 / 59)$ & $0.16(0.13 / 0.17)$ & $0.039(0.036 / 0.040)$ \\
\hline $\mathrm{PM}_{10}\left(\mu \mathrm{g} \mathrm{m}^{-3}\right)$ & $34.9(21.0 / 55.5)$ & & $0.58(1.13 / 0.62)$ & $22.1(19.5 / 24.5)$ & & nd \\
\hline $\mathrm{EC}\left(\mu \mathrm{g} \mathrm{m}^{-3}\right)$ & $0.11(0.09 / 0.17)$ & & $0.03(0.05 / 0.03)$ & $0.31(0.28 / 0.33)$ & & $0.21(0.19 / 0.22)$ \\
\hline $\mathrm{OC}\left(\mu \mathrm{g} \mathrm{m}^{-3}\right)$ & $1.9(1.5 / 3.0)$ & & $0.17(0.16 / 0.15)$ & $3.6(3.3 / 3.9)$ & & $0.16(0.13 / 0.18)$ \\
\hline$T\left({ }^{\circ} \mathrm{C}\right)$ & & $25.6(27.0 / 22.2)$ & & & $23.1(28.8 / 17.5)$ & \\
\hline
\end{tabular}

${ }^{\mathrm{a}}$ Two filter and four PUF samples, i.e. nos. 9, 10, 19, and 22 in Fig. S3. ${ }^{\mathrm{b}}$ One filter and one PUF sample, i.e. nos. 1 and 2 in Fig. S3. ${ }^{\mathrm{c}}$ Co-eluted with 3 NFLT, assuming $c_{3 N F L T}=0$.

lesser extent, in eastern Europe and the western Balkans. The $\mathrm{NO}_{2}(1.2-2.6 \mathrm{ppbv})$, total carbon $\left(3-6 \mu \mathrm{g} \mathrm{m}^{-3}\right)$, and $\mathrm{PM}_{10}$ $\left(10.7-46.3 \mu \mathrm{g} \mathrm{m}^{-3}\right)$ levels during the campaign reflect continental background conditions.

The 4-ring PAH concentrations in samples from the continental site and in background air with urban influence collected at the marine site (urban areas $300-500 \mathrm{~km}$ away) are similar (Table 2). Also, the substance patterns are more similar than when relating all samples at the marine site, i.e. $R^{2}=0.88(P>0.999, t$ test $)$ instead of $R^{2}=0.76$. The investigation of the diffusive air-surface exchange processes during the measurements presented here showed that 4ring PAHs were in fact influenced by secondary emissions, namely throughout day and night from the soil at the continental site (on average 16.3 and $9.3 \mathrm{pg} \mathrm{m}^{-2} \mathrm{~h}^{-1}$ for FLT and PYR, respectively; Degrendele et al., 2016) or occasionally from surface seawater at the marine site (during at least one daytime interval out of in total three of this data subset; Lammel et al., 2016). In the data set from the continental site, we study day-night effects (subsets listed in Tables 13 ): PAH concentrations $\left(c_{\text {tot }}\right)$ were $\approx 60 \%$ higher during the day than during the night, while $c_{\text {tot }}$ of NPAH were by average $\approx 5 \%$ lower during the day (Table 2). NPAHs are subject to photolysis, while PAHs are not. At the site, the PAH concentrations were driven by re-volatilisation from soil, de- termined by temperature variation (Degrendele et al., 2016). For NPAHs (partly primary emitted) this indicates that the higher emissions during the day (due to re-volatilisation and road traffic) were compensated by shorter lifetime. NPAH lifetimes may be limited by heterogeneous photolysis, but available kinetic data are scarce and limited to a few aerosol types (Fan et al., 1996; Feilberg and Nielsen, 2000, 2001; García-Berríos et al., 2017). Also, different NPAH / PAH ratios (the potential NPAH yields), which were 5.6 and $8.9 \%$ at the marine and continental sites, respectively, reflect the combination of emission sources and photochemical sinks. The NPAH / PAH ratios at the two sites were influenced by similar substance patterns upon emission, similar irradiation (summer, no or almost no clouds), and similar deposition velocities $\left(\theta\right.$ in the range of $0.05-0.20$ for $\Sigma_{11} 3-4$-ring NPAH and $\Sigma_{6} 4$-ring PAH, no precipitation), but different re-volatilisation fluxes and different characteristic transport times elapsed. The distance to major urban source areas was 300 to $>1000 \mathrm{~km}$ at the marine and $100-500 \mathrm{~km}$ at the continental site. The NPAH / PAH ratios being lower at the more distant receptor site, the marine site, may suggest that photochemical degradation of NPAHs along transport was on average faster than degradation of the precursors.

The NPAH levels observed in marine background air are the lowest ever reported. Remarkably, the concentrations 
are much lower, by more than 1 order of magnitude, than 1 decade before at the same site during the same season (Tsapakis and Stephanou, 2007). The concentrations observed now are a factor of 4-10 lower than in a forest site in Amazonia 2 decades before (which might have been influenced by biomass burning emissions), a factor of 3 lower (for 2NPYR) than observed at an extremely remote site in the Himalayas 2 decades before (Ciccioli et al., 1996), and comparable to a high-altitude site in the Alps (with the exception of 2NPYR, which was observed 1 order of magnitude higher there in winter; Albinet et al., 2008a; Table 3). The NPAH levels observed at the marine site with influence of pollution and at the continental site are comparable but are also at the lower end of the range spanned by previous observations at rural and remote sites (Table 3).

\subsection{Gas-particle partitioning}

The time-weighted mean NPAH phase distributions $\left(\Sigma_{11} 3-\right.$ 4-ring NPAH) differ, corresponding to $\theta=0.05$ and 0.17 at the marine and continental sites, respectively - despite similar temperatures (Table 1). In contrast, and despite similar temperature ranges, the 4-ring PAHs' $\left(\Sigma_{6} 4\right.$-ring $\left.\mathrm{PAH}\right)$ particulate mass fraction was higher at the marine than at the continental site $(\theta=0.42$ and 0.20 , respectively). Both 4ring PAHs and 3-4-ring NPAHs were more associated with PM in polluted air than in clean air. This trend is weak for PAHs with $\theta=0.02$ for $\Sigma_{6}$ 4-ring PAH in marine background air and 0.07 in background air with urban influence (and $\theta=0.09$ and 0.20 for CHR; Table 2) but is obviously strong for NPAHs, namely $\theta=0.19$ for 2NPYR in marine background air and 0.69 in background air with urban influence, $\approx 0.93$ in polluted continental air, and $\theta=0.01$ for $\Sigma_{11} 3$-4-ring NPAH in marine background air but 0.22 in background air with urban influence (Table 2). The urbaninfluenced air at the marine site is also reflected in a much higher organic carbon (OC) (a factor of 3 higher than the allcampaign mean) and elevated EC (less prominent, $\approx 50 \%$ above mean). This confirms the understanding that gasparticle partitioning of both PAHs (Lohmann and Lammel, 2004; Shahpoury et al., 2016) and NPAHs (Tomaz et al., 2016) is mostly determined by absorption in particulate OM (POM) and adsorption to soot. When comparing polluted air at the continental site and background air with urban influence at the marine site, a strong shift of $\Sigma_{6} 4$-ring PAH towards the particulate phase, $\theta \approx 0.21$ vs. 0.07 , respectively, is found; for $\Sigma_{11} 3$-4-ring NPAH, $\theta$ is similar, i.e. $\approx 0.16 \mathrm{vs.}$ 0.22 , respectively. This phase partitioning trend of the 4-ring PAHs could be explained by sorption to EC, which is a factor of $\approx 2$ higher, but not by OC (only $\approx 20 \%$ higher). In conclusion, these observations consistently indicate that sorption to soot is less significant for gas-particle partitioning of NPAHs than for PAHs.

While NPAHs were significantly phase-shifted $(\theta=0.24$ during daytime but $\theta=0.58$ during night time), this was not the case for 4-ring PAHs $(\theta=0.18$ during daytime and $\theta=0.23$ during night time). This is in line with the perception that the temperature sensitivity of phase change is stronger for the substance class with stronger molecular interactions in the condensed-phase NPAHs. For example, the enthalpies of phase change between air and OC of FLT and NFLT are -98 and $-75 \mathrm{~kJ} \mathrm{~mol}^{-1}$, respectively (OC represented by DMSO; ACD, 2015).

Good agreement is found for the prediction of NPAH partitioning using the multi-phase (three-phase) ppLFER with most values predicted within 1 order of magnitude of the observed values (Fig. 2; quantification of deviations in Sect. S2.3.1). While the sensitivity of assumptions regarding PM phase composition made in the model does not contribute significantly to the deviations ( $\ll 1, \log K_{\mathrm{p}}$ units), a significant part can be attributed to the usage of estimated solute-specific Abraham solvation parameters (taken from ACD , 2015), due to the lack of experimentally based descriptors. For example, for an urban site (Tomaz et al., 2016) it was found that experimentally based descriptors used for 9NPAH lead to better predictions than the estimated descriptors; i.e. root-mean-square errors differed by $0.43 \mathrm{log}$ units. The agreement of the ppLFER prediction is better than assuming absorption (into $\mathrm{OM}$ ) to be the only relevant process ( $K_{\text {oa }}$ model; see Sect. S2.3.2, Fig. S5). The same was found when studying gas-particle partitioning of NPAHs in urban air (Tomaz et al., 2016). This supports the perception that gas-particle partitioning of NPAHs is governed by various molecular interactions with $\mathrm{OM}$, with its polarity being well represented by DMSO, better than by octanol. Earlier, it had been found for eight 3-4-ring NPAHs at urban and rural sites (Li et al., 2016) that the dual model, assuming adsorption (to soot) and absorption (into OM), predicts better than single adsorption (to the total aerosol surface, i.e. Junge-Pankow) or single absorption $\left(K_{\text {oa }}\right)$ models do.

The interactions with the aerosol matrix of 9NPHE (continental site) and 5NACE, 2NFLN, 2NFLT, and 1NPYR (marine site) are less well represented than other NPAHs by the model, as suggested by the low slopes of their $\log K_{\text {pexperimental }} / \log K_{\text {p predicted }}$ relationships. The reason is unknown. Moreover, sampling or sample handling artefacts cannot be excluded, even when the same temperature range, sampler, and sampling protocols are applied across sites with both satisfactory and deficient agreement between predicted and observed $K_{\mathrm{p}}$. Further conclusions are not supported by the limited amount of data and uncertainties on both the model (estimated ppLFER parameters) and experimental (concentrations close to LOQ) sides.

\subsection{Mass size distribution}

The NPAH mass size distribution had its maximum in the $<0.49 \mu \mathrm{m}$ size range at both sites. The 4-ring PAHs mass size distribution had two maxima, $<0.49 \mu \mathrm{m}$ and between 0.95 and $1.5 \mu \mathrm{m}$, at the marine site but only one, at $<0.49 \mu \mathrm{m}$, 
Table 3. Comparison of total $(\mathrm{g}+\mathrm{p})$ concentrations in air, $c_{\mathrm{tot}}\left(\mathrm{pg} \mathrm{m}^{-3}\right)$, with other measurements at remote and rural sites.

\begin{tabular}{|c|c|c|c|c|}
\hline & $\begin{array}{r}\text { 1NPYR } \\
\left(\mathrm{pg} \mathrm{m}^{-3}\right)\end{array}$ & $\begin{array}{r}2 \text { NFLT } \\
\left(\mathrm{pg} \mathrm{m}^{-3}\right)\end{array}$ & $\begin{array}{r}2 \mathrm{NPYR} \\
\left(\mathrm{pg} \mathrm{m}^{-3}\right)\end{array}$ & References \\
\hline Background central Europe, summer 2013 & 1.1 & $15^{\mathrm{a}}$ & 1.3 & this work (continental) \\
\hline Eastern Mediterranean, summer 2012 & 0.74 & $8.6^{\mathrm{a}}$ & 2.5 & this work (marine) \\
\hline Eastern Mediterranean, clean summer 2012 & 0.21 & $3.8^{\mathrm{a}}$ & 0.92 & this work (marine background ${ }^{b}$ ) \\
\hline Eastern Mediterranean, clean summer 2002 & - & 29 & 21 & Tsapakis and Stephanou (2007) \\
\hline Ross Sea coast, Antarctica & $<0.02^{\mathrm{c}}$ & $<0.03^{\mathrm{c}}$ & & Vincenti et al. (2001) \\
\hline Himalayas, Nepal, 1991 & - & - & 3 & Ciccioli et al. (1996) \\
\hline Amazon rainforest, 1993 & 2 & 15 & 8 & Ciccioli et al. (1996) \\
\hline Rural northern Germany, 1991 & - & - & 3 & Ciccioli et al. (1996) \\
\hline Rural Denmark, winter-spring 1982 & $9 \pm 5^{\mathrm{c}}$ & - & - & Nielsen et al. (1984) \\
\hline Semi-rural Denmark, all year 1998-1999 & 40 & 97 & 6.3 & Feilberg et al. (2001) \\
\hline Remote Alps, 2002 & 2.2 & - & - & Schauer et al. (2004) \\
\hline Rural Alps, 2002 & 6.6 & - & - & Schauer et al. (2004) \\
\hline Rural Alps ${ }^{\mathrm{d}}$, winter 2002-2003 & 21 & $96^{\mathrm{a}}$ & 81 & Albinet et al. (2008a) \\
\hline Rural Alps ${ }^{\mathrm{d}}$, summer 2003 & 4.2 & $28^{\mathrm{a}}$ & 5.7 & Albinet et al. (2008a) \\
\hline Remote Alps ${ }^{\mathrm{e}}$, winter 2002-2003 & 2.4 & $1.3^{\mathrm{a}}$ & 14.8 & Albinet et al. (2008a) \\
\hline Remote Alps ${ }^{\mathrm{e}}$, summer 2003 & 0.6 & $1.8^{\mathrm{a}}$ & 0.7 & Albinet et al. (2008a) \\
\hline Rural southern France, 2004 & 0.6 & $2.6^{\mathrm{a}}$ & 1.6 & Albinet et al. (2007) \\
\hline
\end{tabular}

${ }^{\mathrm{a}}$ Co-eluted with 3NFLT, assuming $c_{3 \mathrm{NFLT}}=0 .{ }^{\mathrm{b}}$ Samples $9,10,19$, and 22 in Fig. S3. ${ }^{\mathrm{c}}$ Particulate-phase concentration only. ${ }^{\mathrm{d}}$ Val de Maurienne sites (Albinet et al., 2008a). ${ }^{\text {e }}$ Plan de l'Aiguille site (Albinet et al., 2008a).

at the continental site (Table 1). This is probably related to the presence of aged aerosol at the marine site vs. a larger contribution of fresh aerosols at the continental site. This is, furthermore, supported by the analysis of air mass origins that shows significant influence of urban areas for only few samples at the marine and for all samples at the continental site (Sect. S2).

Sums of NPAHs' and PAHs' mass size distributions are found unimodal with the maximum in particles $<0.49 \mu \mathrm{m}$ except PAHs at the marine site, which shows a second maximum between 1.5 and $3.0 \mu \mathrm{m}$ (Fig. 3). At the marine site, 50 and $69 \%$ of 1NPYR and 2NFLT, respectively, was found associated with particles $<0.45 \mu \mathrm{m} ; 68$ and $86 \%$ with particles $<0.95 \mu \mathrm{m}$; and even more, 83 and $100 \%$ with particles $<0.45 \mu \mathrm{m}$ at the continental site.

$\Sigma_{6} 4$-ring PAH mass size distributions are shifted to larger particles in background air with urban influence as compared to marine background air (both collected at the marine site), i.e. $\mathrm{MMD}=0.19$ and 0.28 , respectively. However, such a trend is not apparent for NPAHs (Table 2). The size shift of PAHs does not correspond to the $\mathrm{PM}_{10}$ mass size distribution: the MMD of $\mathrm{PM}_{10}$ for all samples collected at the marine site was $0.58 \mu \mathrm{m}$, while it was 1.13 and $0.62 \mu \mathrm{m}$ in the marine background air and background air with urban influence data subsets, respectively. The $\mathrm{PM}_{10}$ as well as the OC mass size distributions were bimodal with maxima corresponding to $<0.49$ and 3.0-7.2 $\mu \mathrm{m}$ particles (MMDs listed in Table 2), while the EC mass size distribution was unimodal, with the maximum concentration in the finest fraction. At the continental site, the $\Sigma_{11} 3-4$-ring NPAH mass size distribu- tion was bimodal with maxima corresponding to $<0.49$ and 7.2-10 $\mu \mathrm{m}$ particles, while the $\Sigma_{6} 4$-ring PAH mass size distribution was unimodal, with the maximum concentration in the finest fraction (for all samples as well as for day and night data subsets; Table 1).

The formation of a second maximum, at larger particles than emitted, reflects the redistribution of semi-volatile organics in an aged aerosol and, hence, is expected at receptor sites such as the marine site. This was also observed in polluted air at rural and suburban sites but not at traffic sites or in winter at a rural site, when primary emissions dominated (unimodal; Albinet et al., 2008b; Ringuet et al., 2012b).

\subsection{Substance patterns and NPAH formation during long-range atmospheric transport}

Among the targeted NPAHs and apart from NNAPs, which were the most concentrated, 2NFLT and 3NPHE prevailed at the marine site (accounting together for $\approx 60 \%$ of the NPAH mass, excluding the NNAPs), while at the continental site 9NANT and 2NFLT prevailed (accounting for $\approx 65 \%$ together) (Fig. 1, summarised in Fig. S4). The analytical method did not separate the isomers 2NFLT and 3NFLT, but at receptor sites, far from diesel emissions, it appears justified to assume $c_{2 \mathrm{NFLT}} \gg c_{3 \mathrm{NFLT}}$ (FinlaysonPitts and Pitts, 2000; Zimmermann et al., 2012). The ratio 1 NPYR / 2NPYR is higher, $\approx 1$, at the continental site than at the marine site $(\approx 0.25)$, which reflects the significance of primary sources for polluted air (Atkinson and Arey, 1994; Finlayson-Pitts and Pitts, 2000; Zimmermann et al., 2012). This ratio was found similarly high or even higher at urban 

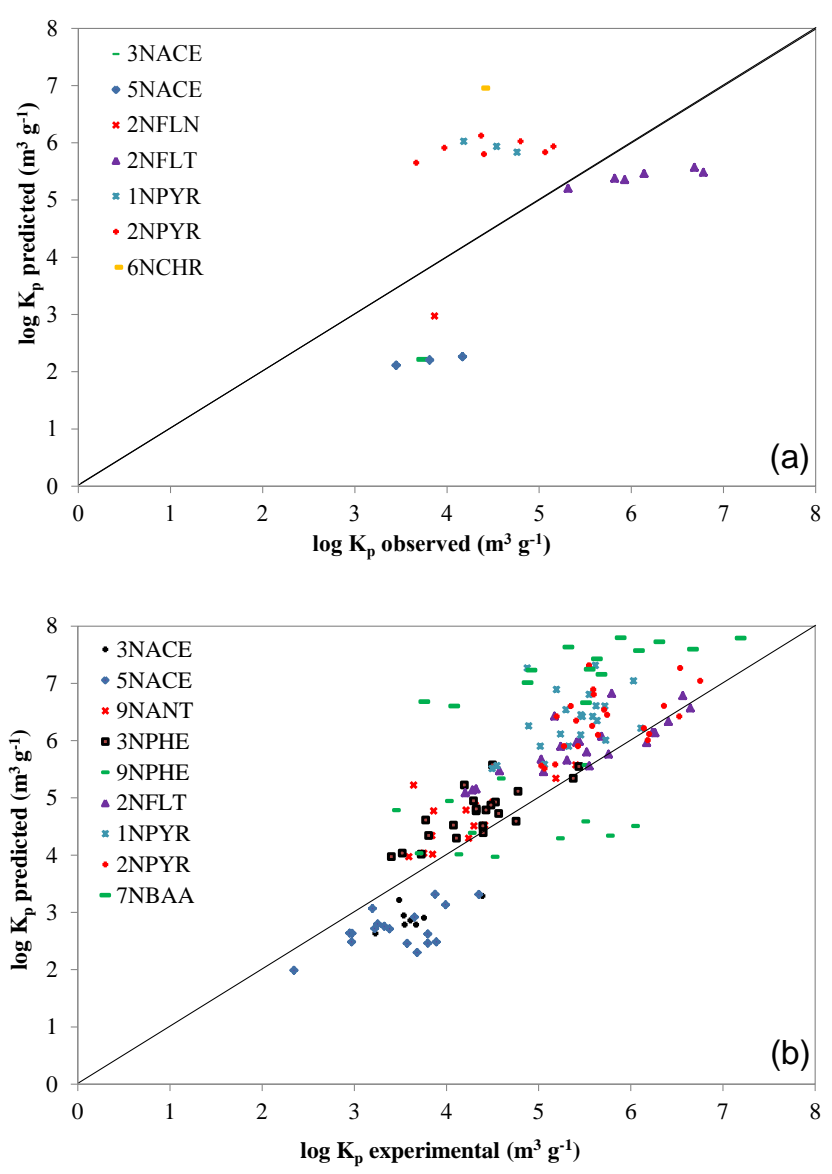

Figure 2. Predicted versus experimental $\log K_{\mathrm{p}}\left(\mathrm{m}^{3}\right.$ air $\left.\mathrm{g}^{-1} \mathrm{PM}\right)$ for NPAHs using the multi-phase ppLFER model at the (a) marine and (b) continental site.

sites (Ringuet et al., 2012c; Tomaz et al., 2016). Similarly, the ratio 2NFLT / 1NPYR, the concentration of a secondarily formed over a primary emitted NPAH, has been used as indicator for fresh emissions (if $<5$ ) vs. photochemically aged air mass (Keyte et al., 2013). These values were $\gg 5$ in 21 out of 22 and 7 out of 8 samples at the marine and continental sites, respectively. The only sample collected at the continental site with elevated primary NPAH $(2 \mathrm{NFLT} / 1 \mathrm{NPYR}=4.3)$ was possibly influenced by emissions from Budapest, which was passed by the advected air within the last hours before arrival. The only sample collected at the marine site with elevated primary NPAH ( 2 NFLT / $1 \mathrm{NPYR}=5.9)$ was indeed directly influenced by emissions into the boundary layer above the Izmir and Istanbul metropolitan areas (urban fractional dose $D_{\mathrm{u}}=5.0 \%$ for samples 1 and 2 in Fig. S3). In conclusion, these results from receptor/background sites confirm the existing knowledge about primary emitted and secondarily formed NPAHs.

The ratio of two secondarily formed NPAHs, 2NFLT / 2NPYR, indicative for daytime vs. night-time formation paths (Atkinson and Arey, 1994; Ciccioli et al., 1996), is found $\approx 2$ at the marine and $\approx 8$ at the continental site (normalised to the precursor ratio, i.e. 2NFLT / 2NPYR / (FLT / PYR); Table 4). Such low values point to daytime (OH-initiated) formation, while night-time ( $\mathrm{NO}_{3}$-initiated) formation was negligible, practically excluded, at the marine site. This is in line with the perception that $\mathrm{NO}_{3}$ must have been very low in this remote environment. $\left(\mathrm{NO}_{x}\right.$ levels at the marine site were in the range $0.2-0.6$ ppbv.) A similar conclusion has been previously drawn in a semi-rural environment (Feilberg et al., 2001).

For 2NFLT and 2NPYR (secondary sources only) and for 1NPYR, which has mostly primary sources (FinlaysonPitts and Pitts, 2000; Ringuet et al., 2012a; Jariyasopit et al., 2014a, b), we infer the potential yields (Table 4). Here, yield is defined as $c_{\mathrm{NPAH}} / c_{\mathrm{PAH}}$ (total concentrations). This yield is called "potential" as it reflects an upper estimate, as other PAH photochemical sinks, such as formation of oxy-PAHs, are neglected. The yield of 2NFLT in polluted air exceeds the one in background air only slightly, while the yield of 2NPYR in polluted air exceeds the one in background air much more (a factor of 3 higher).

As expected, the highest potential yield of 1NPYR is found in polluted air (both sites), reflecting the dominance of primary emissions of 1NPYR. Similarly, higher yields of secondary NPAHs are found for marine background air compared to background air with urban influence (marine site), reflecting the longer reaction times elapsed since $\mathrm{PAH}$ emission. The yield for 2 NFLT, $c_{2 \mathrm{NFLT}} / c_{\mathrm{FLT}}$, which is $\approx 2$ $4 \%$ at both sites, ranges higher than the one for 2NPYR, $c_{2 \mathrm{NPYR}} / c_{\mathrm{PYR}}$, which is found $\approx 0.5-2 \%$. Note that because of the co-elution of 2NFLT and 3NFLT, and neglect of $3 \mathrm{NFLT}$, the so-derived values of $c_{2 \mathrm{NFLT}} / c_{\mathrm{FLT}}$ actually represent upper estimates. Apart from sites which were immediately influenced by PAH sources (road traffic, power plant, biomass burning), only very few studies reported NPAH together with precursor data in both phases of ambient air. $c_{2 \mathrm{NPYR}} / c_{\mathrm{PYR}}=1.0 \%$, similar to our finding at remote sites, but a very high $c_{2 \mathrm{NFLT}} / c_{\mathrm{FLT}}$ of $12.9 \%$ was reported from a suburban site in France in summer during daytime (corresponding values for night time were 2.0 and $9.4 \%$, respectively; Ringuet et al., 2012c). 2NFLT was not separated from 3NFLT (similar to our data set). A suburban site will be influenced by direct 3 NFLT emissions, such that $c_{2 \mathrm{NFLT}} / c_{\mathrm{FLT}}$ is an upper estimate. Many lower ratios, $c_{2 \mathrm{NFLT}} / c_{\mathrm{FLT}}=0.20 \%$ and $c_{2 \mathrm{NPYR}} / c_{\mathrm{PYR}}=0.08 \%$, were reported as the median values for 90 sites of various categories, rural and urban, in northern China in summer (Lin et al., 2015). These yields are somewhat higher for the subset of the rural sites. The potential yields found at the marine site in our study are close to the yields for $\mathrm{OH}$-initiated photochemistry observed in laboratory experiments under high $\mathrm{NO}_{x}$ conditions, i.e. $3 \%$ for $c_{2 \mathrm{NFLT}} / c_{\mathrm{FLT}}$ and $0.5 \%$ for $c_{2 \mathrm{NPYR}} / c_{\mathrm{PYR}}$ (Atkinson and Arey, 1994). 


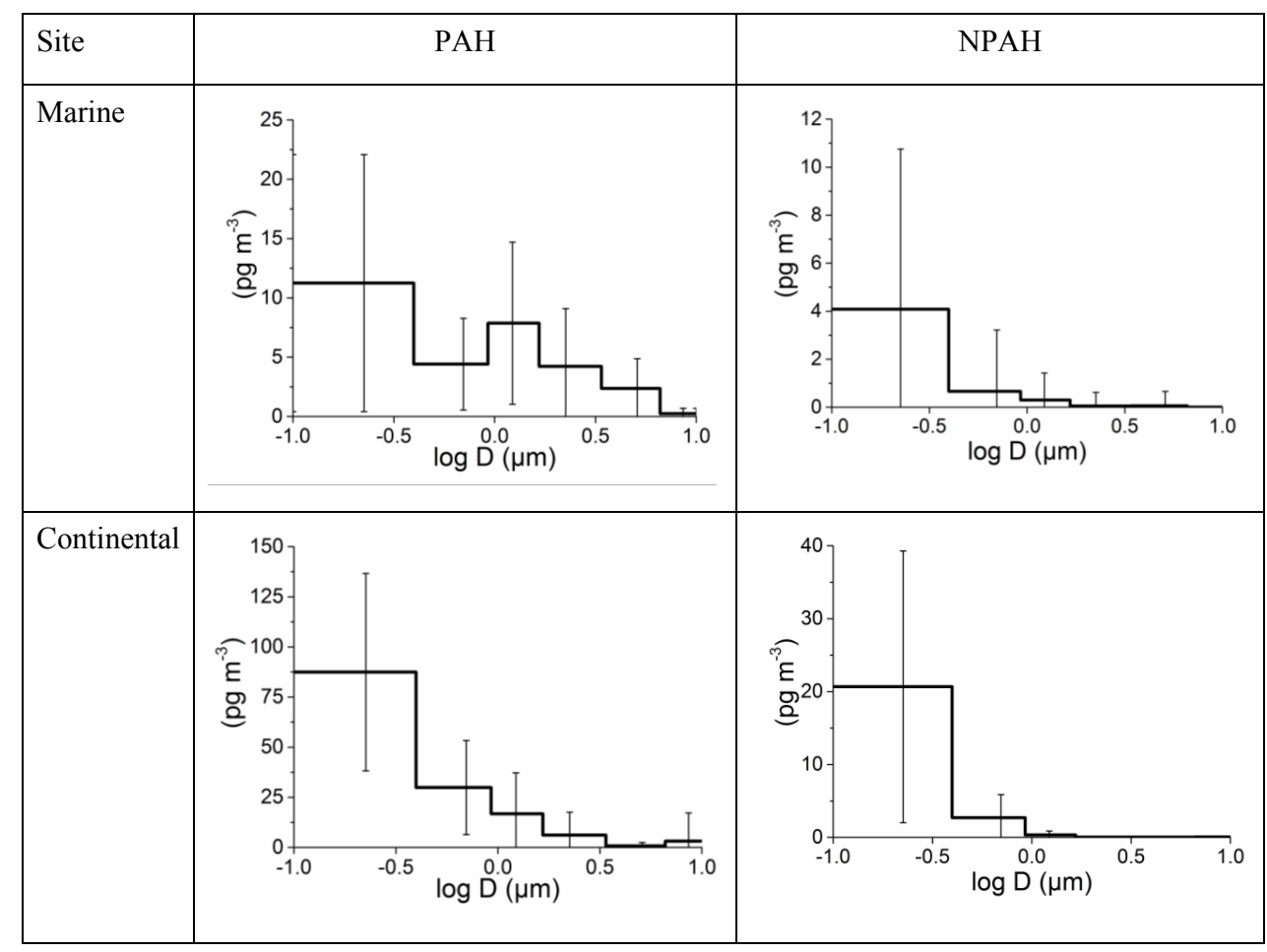

Figure 3. Time-weighted mean $\Sigma_{6} 4$-ring PAH and $\Sigma_{11}$ 3-4-ring NPAH mass size distributions ( $\mathrm{pg} \mathrm{m}^{-3}$ ) at the marine and continental sites. The error bars show the standard deviation from the campaign mean.

Table 4. Selected 4-ring PAHs and primary and secondary 3-4-ring NPAH total $(\mathrm{g}+\mathrm{p})$ time-weighted mean concentrations $\pm \sigma\left(\mathrm{pg}^{-3}\right)$. Potential yields, $c_{\mathrm{NPAH}} / c_{\mathrm{PAH}}$, in parentheses. $\sigma$ given for $n>2$.

\begin{tabular}{|c|c|c|c|c|c|}
\hline \multirow[t]{2}{*}{ Site } & \multirow[b]{2}{*}{$\begin{array}{l}\text { Data } \\
\text { subset }\end{array}$} & \multicolumn{3}{|c|}{ Marine } & \multirow{2}{*}{$\begin{array}{r}\text { Continental } \\
\text { all } \\
(n=22)\end{array}$} \\
\hline & & $\begin{array}{r}\text { all } \\
\left(n=8^{\mathrm{a}}\right)\end{array}$ & $\begin{array}{r}\text { marine } \\
\text { background } \\
\left(n=2^{\mathrm{b}}\right)\end{array}$ & $\begin{array}{r}\text { background with } \\
\text { urban influence } \\
\left(n=2^{\mathrm{c}}\right)\end{array}$ & \\
\hline \multirow[t]{2}{*}{ Primary } & FLT & $213 \pm 161$ & 161 & 259 & $342 \pm 215$ \\
\hline & PYR & $146 \pm 130$ & 103 & 188 & $226 \pm 131$ \\
\hline \multirow[t]{3}{*}{ Primary and secondary (potential yield) } & $2 \mathrm{NFLN}^{\mathrm{d}}$ & $0.038 \pm 0.12$ & $<0.18$ & 0.15 & $0.034 \pm 0.044$ \\
\hline & 1NPYR & $0.62 \pm 1.1$ & 0.21 & 1.4 & $1.1 \pm 0.6$ \\
\hline & & $(0.4 \pm 0.2 \%)$ & $(0.2 \%)$ & $(0.7 \%)$ & $(0.6 \pm 0.3 \%)$ \\
\hline \multirow[t]{4}{*}{ Secondary (yield) } & $2 \mathrm{NFLT}^{\mathrm{e}}$ & $7.7 \pm 8.5$ & 1.68 & 11.0 & $15 \pm 10$ \\
\hline & & $(3.6 \pm 2.0 \%)$ & $(1.0 \%)$ & $(4.2 \%)$ & $(6.5 \pm 7.5 \%)$ \\
\hline & 2NPYR & $2.2 \pm 2.6$ & 0.92 & 3.3 & $1.3 \pm 1.7$ \\
\hline & & $(1.5 \pm 0.7 \%)$ & $(0.9 \%)$ & $(1.8 \%)$ & $(0.74 \pm 1.09 \%)$ \\
\hline
\end{tabular}

${ }^{a}$ Eight filter and 21 PUF samples. ${ }^{\mathrm{b}}$ Two filter and six PUF samples, i.e. nos. 9-10 and 19-22 in Fig. S3 (urban fractional dose $D_{\mathrm{u}}=0.4 \%$ ). ${ }^{\mathrm{c}}$ Two filter and five PUF samples, i.e. nos. $1-2$ and $15-18$ in Fig. $\mathrm{S} 3\left(D_{\mathrm{u}}=3.1 \%\right)$. ${ }^{\mathrm{d}}$ No yield given as $c_{\mathrm{FLN}}$ not quantified. ${ }^{\mathrm{e}}$ Co-eluted with $3 \mathrm{NFLT}$, assuming $c_{3 \mathrm{NFLT}}=0$.

\section{Conclusions}

For the first time, pollution contained in individual background air samples was quantified by means of a fractional dose. The fractional dose indicated how much the collected volume of air had been exposed to an urban boundary layer within a given time horizon. This is found suitable to discriminate among samples and discuss results, clearly beyond qualitative reasoning on back trajectories alone. The concept could be applied to any type of georeferenced origin and might be useful to track the influence of land use of various kinds or ship and aircraft routes. 
Our measurements confirmed the occurrence of mutagenic NPAHs, earlier reported from polluted atmospheric environments of America, Europe, and Asia, for the European background atmosphere and the outflow of Europe as well. These substances are obviously subject to intercontinental transport and might indeed be distributed ubiquitously. The mass size distribution is determined by the particle size upon emission (primary NPAHs), and condensation and redistribution in the aerosol along transport, hence, do not include the short-lived coarse mass fraction. This indicates a high long-range transport potential. However, the observation of 3.8 and $0.92 \mathrm{pg} \mathrm{m}^{-3}$ of 2NFLT and 2NPYR, respectively, measured at the south-eastern outflow of Europe (the lowest ever reported concentrations; Table 3), may indicate that their abundance in the remote global environment could be less than anticipated. Earlier, this was based on a single measurement of $2 \mathrm{NPYR}, 3 \mathrm{pg} \mathrm{m}^{-3}$, at an extremely remote site in central Asia 2 decades before (Ciccioli et al., 1996). Moreover, this air, classified as marine background, was not completely clean but had been exposed to a non-zero fractional urban pollution dose $(0.4 \%$ of the total, time horizon of 2 days). More measurements at remote sites should verify NPAH levels globally. PAHs have been abated significantly in Europe during the last decades (EEA, 2014), which should also be reflected in long-term trends of their derivatives. However, a temporal trend for the Aegean or the south-eastern outflow of Europe in summer cannot be inferred based on current and earlier (2002; Tsapakis and Stephanou, 2007) campaign data. NPAHs should be included in monitoring programmes to better assess the exposure of human health hazards of atmospheric pollution, even in remote areas.

Our understanding of NPAH formation in ambient air is still rudimentary. Both the kinetics of NPAH formation and photolysis remain to be quantitatively studied under conditions of the background atmosphere, i.e. low $\mathrm{NO}_{x}$, and on various aerosol matrices, including sea salt. More studies into NPAH atmospheric fate, both field observations and kinetic data, are needed in order to assess and quantify spatial and temporal trends, the long-range transport potential, and persistence.

Data availability. Data used in this study are available upon request to the corresponding author.

\section{The Supplement related to this article is available online at doi:10.5194/acp-17-6257-2017-supplement.}

Competing interests. The authors declare that they have no conflict of interest.
Acknowledgements. We thank Christos I. Efstathiou (Masaryk University), András Hoffer, Gyula Kiss (MTA-PE Air Chemistry Research Group, Veszprém), Jiři Kohoutek (MU), Giorgos Kouvarakis (University of Crete, Iraklion), and Lajos Szöke (Hungarian Meteorological Service) for on-site support; Giorgos Kouvarakis and Krisztina Labancz (Hungarian Meteorological Service) for meteorological and trace gas data; Michael H. Abraham (University College London) for providing ppLFER solute descriptors; Ignacio Pisso (NILU, Kjeller, Norway) for model post-processing scripts; and Céline Degrendele (MU) and Manolis Tsapakis (Hellenic Centre for Marine Research, Gournes) for discussions. This research was supported by the Czech Science Foundation (no. P503 16-11537S), the Czech Ministry of Education, Youth and Sports (nos. LO1214 and LM2015051), and the European Union FP7 (no. 262254, ACTRIS).

Edited by: T. Karl

Reviewed by: two anonymous referees

\section{References}

Abraham, M. H.: Scales of solute hydrogen-bonding: their construction and application to physicochemical and biochemical processes, Chem. Soc. Rev., 22, 73-83, 1993.

ACD: ACD/Labs Absolv Software, Advanced Chemistry Development, Toronto, Canada, 2015.

Albinet, A., Leoz-Garziandia, E., Budzinski, H., and Villenave, E.: Simultaneous analysis of oxygenated and nitrated polycyclic aromatic hydrocarbons on standard reference material 1649a (urban dust) and on natural ambient air samples by gas chromatographymass spectrometry with negative ion chemical ionisation, J. Chrom. A, 1121, 106-113, 2006.

Albinet, A., Leoz-Garziandia, E., Budzinski, H., and Villenave, E.: Polycyclic aromatic hydrocarbons (PAHs), nitrated PAHs and oxygenated PAHs in ambient air of the Marseilles area (South of France): Concentrations and sources, Sci. Total Environ., 384, 280-292, 2007.

Albinet, A., Leoz-Garziandia, E., Budzinski, H., Villenave, E., and Jaffrezo, J. L.: Nitrated and oxygenated derivatives of polycyclic aromatic hydrocarbons in the ambient air of two French alpine valleys part 1: concentrations, sources and gas/particle partitioning, Atmos. Environ., 42, 43-54, 2008a.

Albinet, A., Leoz-Garziandia, E., Budzinski, H., Villenave, E., and Jaffrezo, J. L.: Nitrated and oxygenated derivatives of polycyclic aromatic hydrocarbons in the ambient air of two French alpine valleys part 2: Particle size distribution, Atmos. Environ., 42, 5564, 2008b.

Alves, C. A., Vicente, A. M. P., Gomes, J., Nunes, T., Duarte, M., and Bandowe, B. A. M.: Polycyclic aromatic hydrocarbons (PAHs) and their derivatives (oxygenated-PAHs, nitrated-PAHs and azaarenes) in size-fractionated particles emitted in an urban road tunnel, Atmos. Res., 180, 128-137, 2016.

Arey, J.: Atmospheric reactions of of PAHs including formation of nitro-arenes. In: The handbook of Environmental Chemistry, Vol 3I, PAHs and Related Compounds, edited by: Neilson, A. H., Springer, Berlin, 347-385, 1998.

Arey, J., Atkinson, R., Zielinska, B., and McElroy, P. A.: Diurnal concentrations of volatile polycyclic aromatic hydrocarbons and 
nitroarenes during a photochemical air pollution episode in Glendora, California, Environ. Sci. Technol., 23, 321-327, 1989.

Atkinson, R. and Arey, J.: Atmospheric chemistry of polycyclic aromatic hydrocarbons: Formation of atmospheric mutagens, Environ. Health Persp., 102, 117-126. 1994.

Bamford, H. A. and Baker, J. E.: Nitro-polycyclic aromatic hydrocarbon concentrations and sources in urban and suburban atmospheres of the Mid-Atlantic region, Atmos. Environ., 37, $2077-$ 2091, 2003.

Barrado, A. I., García, S., Sevillano, M. L., Rodríguez, J. A., and Barrado, E.: Vapor-phase concentrations of PAHs and their derivatives determined in a large city: Correlations with their atmospheric aerosol, Chemosphere, 93, 1678-1684, 2013.

Borbély-Kiss, I., Haszpra, L., Koltay, E., László, S., Mészáros, A., Mészáros, E., and Szabó, S.: Elemental concentrations and regional signatures in atmospheric aerosols over Hungary, Phys. Scripta, 37, 299-304, 1988.

Ciccioli, P., Cecinato, A., Brancaleoni, E., Frattoni, M., Zacchei, P., Miguel, A., and de Castro Vasconcellos, P.: Formation and transport of 2-nitrofluoranthene and 2-nitropyrene of photochemical origin in the troposphere, J. Geophys. Res., 101, 19567-19582, 1996.

Claxton, L. D., Matthews, P. P., and Warren, S. H.: The genotoxicity of ambient outdoor air, a review: Salmonella mutagenicity, Mutation Res. Rev., 567, 347-399, 2004.

Degrendele, C., Audy, O., Hofman, J., Kučerik, J., Kukučka, P., Mulder, M. D., Přibylová, P., Prokeš, R., Šáňka, M., Schaumann, G. E., and Lammel, G.: Diurnal variations of air-soil exchange of semi-volatile organic compounds (PAHs, PCBs, OCPs and PBDEs) in a central European receptor area, Environ. Sci. Technol., 50, 4278-4288, 2016.

Draxler, R. R. and Rolph, G. D.: HYSPLIT (HYbrid SingleParticle Lagrangian Integrated Trajectory) Model access via NOAA ARL READY, NOAA Air Resources Laboratory, Silver Springs, USA, available from: http://www.arl.noaa.gov/ready/ hysplit4.html (last access: 20 December 2016), 2003.

EEA: European emission inventory report 1990-2012 under the UNECE Convention on Long-range Transboundary Air Pollution (LRTAP), European Environment Agency Technical Report No. 12/2014, Copenhagen, 132 pp., 2014.

EMEP: Transboundary particulate matter, photo-oxidants, acidifying and eutrophying components, Co-operative Programme for Monitoring and Evaluation of the Long-range Transmission of Air Pollutants in Europe, EMEP Report No. 1/2015, Oslo, $150+78$ pp., available from: http://emep.int/publ/reports/ 2015/EMEP_Status_Report_1_2015.pdf (last access: 20 December 2016), 2015.

Endo, S. and Goss, K. U.: Applications of poly-parameter linear free energy relationships in environmental chemistry, Environ. Sci. Technol., 48, 12477-12491, 2014.

Fan, Z. H., Kamens, R. M., Hu, J. X., Zhang, J. B., and McDow, S.: Photostability of nitro-polycyclic aromatic hydrocarbons on combustion soot particles in sunlight, Environ. Sci. Technol., 30, 1358-1364, 1996.

Feilberg, A. and Nielsen, T.: Effect of aerosol chemical composition on the photodegradation of nitro-PAHs, Environ. Sci. Technol., 34, 789-797, 2000.
Feilberg, A. and Nielsen, T.: Photodegradation of nitro-PAHs in viscous organic media used as models of organic aerosols, Environ. Sci. Technol., 35, 108-113, 2001.

Feilberg, A., Poulsen, M. W. B., Nielsen, T., and Skov, H.: Occurrence and sources of particulate nitro polycyclic aromatic hydrocarbon in ambien air in Denmark, Atmos. Environ., 35, 353-366, 2001.

Finizio, A., Mackay, D., Bidleman, T., and Harner, T.: Octanol-air partition coefficient as a predictor of partitioning of semi-volatile organic chemicals to aerosols, Atmos. Environ., 31, 2289-2296, 1997.

Finlayson-Pitts, B. J. and Pitts, J. N.: Chemistry of the Upper and Lower Atmosphere: Theory, Experiments, Application, San Diego, Academic Press, USA, 2000.

García-Berríos, Z. I., Arce, R., Burgos-Martínez, M., and BurgosPolanco, N.D.: Phototransformations of environmental contaminants in models of the aerosol: 2 and 4-nitropyrene, J. Photochem. Photobio. A, 332, 131-140, 2017.

Garner, R. C., Stanton, C. A., Martin, C. N., Chow, F. L., Thomas, W., Hübner, D., and Herrmann, R.: Bacterial mutagenicity and chemical analysis of polycyclic aromatic hydrocarbons and some nitro derivatives in environmental samples collected in West Germany, Environ. Mutagen., 8, 109-117, 1986.

Goss, K. U.: Predicting the equilibrium partitioning of organic compounds using just one linear solvation energy relationship (LSER), Fluid Phase Equilibr., 233, 19-22, 2005.

Goss, K. U. and Schwarzenbach, R. P.: Linear free energy relationships used to evaluate equilibrium partitioning of organic compounds, Environ. Sci. Technol., 35, 1-9, 2001.

Grosjean, D., Fung, K., and Harrison, J.: Interactions of polycyclic aromatic hydrocarbons with atmospheric pollutants, Environ. Sci. Technol., 17, 673-679, 1983.

Halsall, C. J., Sweetman, A. J., Barrie, L. A., and Jones, K. C.: Modelling the behaviour of PAHs during atmospheric transport from the United Kingdom to the Arctic, Atmos. Environ., 35, 255-267, 2001.

Hayakawa, K.: Environmental behaviors and toxicities of polycyclic aromatic hydrocarbons and nitropolycyclic aromatic hydrocarbons, Chem. Pharm. Bull., 64, 83-94, 2016.

Inomata, S., Fushimi, A., Sato, K., Fujitani, Y., and Yamada, H.: 4Nitrophenol, 1-nitropyrene, and 9-nitroanthracene emissions in exhaust particles from diesel vehicles with different exhaust gas treatments, Atmos. Environ., 110, 93-102, 2015.

Jaenicke, R.: Aerosol physics and chemistry, Landolt-Börnstein Neue Serie b, 4, 391-457, 1988.

Jariyasopit, N., Zimmermann, K., Schrlau, J., Arey, J., Atkinson, R., Yu, T. W., Dashwood, R. H., Tao, S., and Massey Simonich, S. L.: Novel NPAH formation from heterogeneous reactions of PAHs with $\mathrm{NO}_{2}, \mathrm{NO}_{3} / \mathrm{N}_{2} \mathrm{O}_{5}, \mathrm{OH}$ radicals, and $\mathrm{OH}$ radicals: Prediction, laboratory studies and mutagenicity, Environ. Sci. Technol., 48, 412-419, 2014a.

Jariyasopit, N., Zimmermann, K., Schrlau, J., Arey, J., Atkinson, R., Yu, T. W., Dashwood, R. H., Tao, S., and Massey Simonich, S. L.: Heterogeneous reactions of particulate matter-bound PAHs and NPAHs with $\mathrm{NO}_{3} / \mathrm{N}_{2} \mathrm{O}_{5}, \mathrm{OH}$ radicals, and $\mathrm{O}_{3}$ under simulated long-range atmospheric transport conditions: Reactivity and mutagenicity, Environ. Sci. Technol., 48, 10155-10164, 2014b. 
Keyte, I. J., Harrison, R. M., and Lammel, G.: Chemical reactivity and long-range transport potential of polycyclic aromatic hydrocarbons - a review, Chem. Soc. Rev., 42, 9333-9391, 2013.

Keyte, I. J., Albinet, A., and Harrison, R. M.: On-road traffic emissions of polycyclic aromatic hydrocarbons and their oxy- and nitro- derivative compounds measured in road tunnel environments, Sci. Total Environ., 566-567, 1131-1142, 2016.

Kouvarakis, G., Tsigaridis, K., Kanakidou, M., and Mihalopoulos, N.: Temporal variations of surface regional background ozone over Crete Island in the Southeast Mediterranean, J. Geophys. Res., 105, 4399-4407, 2000.

Lafontaine, S., Schrlau, J., Butler, J., Jia, Y. L., Harper, B., Harris, S., Bramer, L. M., Waters, K. M., Harding, A., and Massey Simonich, S. L.: Relative influence of trans-Pacific and regional atmospheric transport of PAHs in the Pacific Northwest, U.S, Environ. Sci. Technol., 49, 13807-13816, 2015.

Lammel, G., Audy, O., Besis, A., Efstathiou, C., Eleftheriadis, K., Kohoutek, J., Kukučka, P., Mulder, M.D., Přibylová, P., Prokeš, R., Rusina, T., Samara, C., Sofuoglu, A., Sofuoglu, S. C., Taşdemir, Y., Vassilatou, V., Voutsa, D., and Vrana, B.: Air and seawater pollution and air-sea gas exchange of persistent toxic substances in the Aegean Sea: spatial trends of PAHs, PCBs, OCPs and PBDEs, Environ. Sci. Pollut. R., 22, 11301-11313, 2015.

Lammel, G., Meixner, F. X., Vrana, B., Efstathiou, C. I., Kohoutek, J., Kukucka, P., Mulder, M. D., Pribylová, P., Prokeš, R., Rusina, T. P., Song, G.-Z., and Tsapakis, M.: Bidirectional air-sea exchange and accumulation of POPs (PAHs, PCBs, OCPs and PBDEs) in the nocturnal marine boundary layer, Atmos. Chem. Phys., 16, 6381-6393, doi:10.5194/acp-16-6381-2016, 2016.

Li, W., Shen, G. F., Yuan, C. Y., Wang, C., Shen, H. Z., Jiang, H., Zhang, Y. Y., Chen, Y. C., Su, S., Lin, N., and Tao, S.: The gas/particle partitioning of nitro- and oxy-polycyclic aromatic hydrocarbons in the atmosphere of northern China, Atmos. Res., 172-173, 66-73, 2016.

Lin, Y., Qiu, X. H., Ma, Y. Q., Ma, J., Zheng, M., and Shao, M.: Concentrations and spatial distribution of polycyclic aromatic hydrocarbons (PAHs) and nitrated PAHs (NPAHs) in the atmosphere of North China, and the transformation from PAHs to NPAHs, Environ. Pollut., 196, 164-170, 2015.

Lohmann, R. and Lammel, G.: Adsorptive and absorptive contributions to the gas particle partitioning of polycyclic aromatic hydrocarbons: State of knowledge and recommended parameterisation for modelling, Environ. Sci. Technol., 38, 3793-3803, 2004.

Masclet, P., Pistikopoulos, P., Beyne, S., and Mouvier, G.: Longrange transport and gas/particle distribution of polycyclic aromatic hydrocarbons at a remote site in the Mediterranean sea, Atmos. Environ., 22, 639-650, 1988.

Melymuk, L., Bohlin-Nizzetto, P., Prokeš, R., Kukučka, P., and Klánová, J.: Sampling artifacts in active air sampling of semivolatile organic contaminants: Comparing theoretical and measured artifacts and evaluating implications for monitoring networks, Environ. Pollut., 217, 97-106, 2016.

Mihalopoulos, N., Stephanou, E., Pilitsidis, S., Kanakidou, M., and Bousquet, P.: Atmospheric aerosol composition above the Eastern Mediterranean region, Tellus B, 49, 314-326, 1997.

Nielsen, T., Seitz, B., and Ramdahl, T.: Occurrence of nitro-PAH in the atmosphere in a rural area, Atmos. Environ., 18, 2159-2165, 1984.
Pandis, S. N., Baltensperger, U., Wolfenbarger, J. K., and Seinfeld, J. H.: Inversion of aerosol data from the epiphaniometer, J. Aerosol Sci., 22, 417-428, 1991.

Pankow, J. F.: Overview of the gas phase retention volume behaviour of organic compounds on polyurethane foam, Atmos. Environ., 23, 1107-1111, 1989.

Pitts, J. N., Arey, J., Zielinska, B., Winer, A. M., and Atkinson, R.: Determination of 2-nitro-fluoranthene and 2-nitropyrene in ambient particulate organic matter: Evidence for atmospheric reactions, Atmos. Environ., 19, 1601-1608, 1985.

Ramdahl, T., Zielinska, B., Arey, J., Atkinson, R., Winer, A. M., and Pitts, J. N.: Ubiquitous occurrence of 2-nitro-fluoranthene and 2-nitropyrene in air, Nature, 321, 425-427, 1986.

Reisen, F. and Arey, J.: Atmospheric reactions influence seasonal PAH and nitro-PAH concentrations in the Los Angeles Basin, Environ. Sci. Technol., 39, 64-73, 2005.

Ringuet, J., Albinet, A., Leoz-Garziandia, E., Budzinski, H., and Villenave, E.: Reactivity of polycyclic aromatic compounds (PAHs, NPAHs and OPAHs) adsorbed on natural aerosol particles exposed to atmospheric oxidants, Atmos. Environ., 61, 1522, 2012a.

Ringuet, J., Leoz-Garziandia, E., Budzinski, H., Villenave, E., and Albinet, A.: Particle size distribution of nitrated and oxygenated polycyclic aromatic hydrocarbons (NPAHs and OPAHs) on traffic and suburban sites of a European megacity: Paris (France), Atmos. Chem. Phys., 12, 8877-8887, doi:10.5194/acp-12-88772012, $2012 b$.

Ringuet, J., Albinet, A., Leoz-Garziandia, E., Budzinski, H., and Villenave, E.: Diurnal/nocturnal concentrations and sources of particulate-bound PAHs, OPAHs and NPAHs at traffic and suburban sites in the region of Paris (France), Sci. Total Environ., 437, 297-305, 2012c.

Schauer, C., Niessner, R., and Pöschl, U.: Analysis of nitrated polycyclic aromatic hydrocarbons by liquid chromatography with fluorescence and mass spectrometry detection: air particulate matter, soot, and reaction product studies, Anal. Bioanal. Chem., 378, 725-736, 2004.

Schuetzle, D.: Sampling of vehicle emissions for chemical analysis and biological testing, Environ. Health Perspect., 47, 65-80, 1983.

Shahpoury, P., Lammel, G., Albinet, A., Sofuoğlu, A., Dumanoğlu, Y., Sofuoğlu, S.C., Wagner, Z., and Ždimal, J.: Model evaluation for gas-particle partitioning of polycyclic aromatic hydrocarbons in urban and non-urban sites in Europe - Comparison between single- and poly-parameter linear free energy relationships based on a multi-phase aerosol scenario, Environ. Sci. Technol., 50, 12312-12319, 2016.

Stohl, A., Hitzenberger, M., and Wotawa, G.: Validation of the Lagrangian particle dispersion model FLEXPART against large scale tracer experiments, Atmos. Environ., 32, 4245-4264, 1998.

Stohl, A., Forster, C., Frank, A., Seibert, P., and Wotawa, G.: Technical note: The Lagrangian particle dispersion model FLEXPART version 6.2, Atmos. Chem. Phys., 5, 2461-2474, doi:10.5194/acp-5-2461-2005, 2005.

Tomaz, S., Shahpoury, P., Jaffrezo, J. L., Lammel, G., Perraudin, E., Villenave, E., and Albinet, A.: One year study of polycyclic aromatic compounds at an urban site in Grenoble (France): seasonal variations, gas/particle partitioning and cancer risk estimation, Sci. Total Environ., 565, 1071-1083, 2016. 
Tsapakis, M. and Stephanou, E. G.: Diurnal cycle of PAHs, nitroPAHs and oxy-PAHs in a high oxidant capacity marine background atmosphere, Environ. Sci. Technol., 41, 8011-8017, 2007.

Vincenti, M., Maurino, V., Minero, C., and Pelizzetti, E.: Determination of nitro-substituted polycyclic aromatic hydrocarbons in the Antarctic airborne particulsate, Int. J. Environ. An. Ch., 79, 257-272, 2001.

Vogelezang, D. H. P. and Holtslag, A. A. M.: Evaluation and model impacts of alternative boundary-layer height formulations, Bound.-Layer Meteorol., 81, 245-269, 1996.

Vrekoussis, M., Liakakou, E., Kocak, M., Kubilay, N., Oikonomou, K., Sciare, J., and Mihalopoulos, N.: Seasonal variability of optical properties of aerosols in the Eastern Mediterranean, Atmos. Environ., 39, 7083-7094, 2005.
Yamasaki, H., Kuwata, K., and Miyamoto, H.: Effects of ambient temperature on aspects of airborne polycyclic aromatic hydrocarbons, Environ. Sci. Technol., 16, 189-194, 1982.

Zimmermann, K., Atkinson, R., Arey, J., Kojima, Y., and Inazu, K.: Isomer distributions of molecular weight 247 and 273 nitroPAHs in ambient samples, NIST diesel SRM, and from radicalinitiated chamber reactions, Atmos. Environ., 55, 431-439, 2012.

Zimmermann, K., Jariyasopit, N., Massey Simonich, S. L., Tao, S., Atkinson, R., and Arey, J.: Formation of NPAHs from the heterogeneous reaction of ambient particle-bound PAHs with $\mathrm{N}_{2} \mathrm{O}_{5} / \mathrm{NO}_{3} / \mathrm{NO}_{2}$, Environ. Sci. Technol., 47, 8434-8442, 2013. 